\title{
A pesquisa em Ciências da Comunicação com o uso das novas mídias digitais
}

\author{
Paulo Eduardo Silva Lins Cajazeira \\ Universidade Federal do Cariri \\ E-mail: paulo.cajazeira@ufca.edu.br
}

\begin{abstract}
Resumo
Este estudo procura compreender as alterações no processo da produção e divulgação científica com o uso das novas mídias digitais. Para tanto, verificouse que os métodos qualitativos de pesquisa, na produção científica, são afetados pelo advento da Internet desde o pensar no grupo de entrevistados à elaboração dos questionários on-line e a sua efetiva aplicação. O nosso objetivo é discutir o papel das tecnologias digitais no processo de coleta, análise de dados, divulgação e a participação na pesquisa científica. Como objeto de análise, nos focamos na observação de duas pesquisas na área de Ciências da Comunicação.

A primeira realizada no âmbito do Laboratório de Comunicação e Conteúdos On-line da Universidade da Beira Interior (Portugal) e a segunda coordenada em conjunto por investigadores brasileiros da Universidade Federal do Paraná (Brasil) e da Universidade de Brasília (Brasil) realizada com participantes de diferentes países, com identidades culturais similares, de cunho qualitativo, com objetivos e contextos que ilustram o modo como a instrumentalização dos questionários online na coleta de dados pode ser realizado utilizando-se de Redes Sociais On-line e de recursos da Internet para adesão de novos públicos.
\end{abstract}

Palavras-chave: tecnologia digital; ciência; métodos qualitativos; pesquisa científica.

\begin{abstract}
This study aims to understand the changes in the process of production and science propagation using of new digital media. Therefore, it was verified that qualitative methods of research, in the scientific production, are affected by the

advent of the Internet from the thinking of the interviewee group to the online questionnaires elaboration and their effective implementation. Our goal is to discuss the role of the digital technologies in the collection process, data analy-
\end{abstract}


sis, propagation and participation in scientific research. As the object of analysis, we focus on the observation of two studies in Communication Sciences area. The first one accomplished in the Laboratory of Communication and Online Content from the University of Beira Interior (Portugal) and the second coordinated jointly by brazilian researchers at the Federal University of Paraná (Brazil) and the National University of Brasilia (Brazil) fulfilled with participants from different countries with similar cultural identities, with qualitative nature, with goals and contexts that illustrate how the instrumentalization of online questionnaires in data collection can be executed using online Social Networks and Internet resources for new audiences accession.

Keywords: digital technology; science; qualitative methods; scientific research.

\section{Introdução}

$\mathrm{O}$ objetivo deste estudo é discutir o papel das tecnologias digitais no processo de coleta, análise de dados e divulgação e participação de pesquisas qualitativas com o uso de inquéritos on-line e redes digitais na Internet. Acreditamos que, a tecnologia utilizada altera o processo da produção científica. Se antes escolhíamos um grupo de entrevistados na execução de pesquisas qualitativas e fazíamos as entrevistas face a face, hoje, com as possibilidades infinitas da Internet, ampliam-se de maneira significativa as redes de contatos e novas adesões são incluídas no processo de construção do conhecimento. Assim, estreitam-se as fronteiras comunicacionais entre pesquisadores e pesquisados, produtores de conhecimento e leitores. Com isso, temos um universo mais representativo e válido de resultados que nos permitem evidenciar outros aspectos da investigação em realidades distintas.

Outra alteração processual verificada é a utilização de redes sociais digitais na divulgação e compartilhamento de trabalhos científicos oriundos de revistas, repositórios de universidades e bibliotecas virtuais. Ademais, o discurso em redes sociais digitais na divulgação do conteúdo científico adquire características muito particulares, ora se aproximando da oralidade, ora da escrita, e o fazer ciência é transformado pela tecnologia ao aproximar-se de um número infinito de novos leitores. As novas mídias digitais assumem um papel fundamental no fazer ciência e divulgar o conhecimento científico. 
Criamos o seguinte problema de pesquisa neste estudo: "Em que medida as novas mídias digitais na Internet podem moldar a análise do investigador, bem como ampliar a divulgação dos resultados na área das Ciências da Comunicação?". A nossa hipótese é apoiada em uma perspectiva teórica, na qual o conhecimento é produzido por um coletivo de seres conectados digitalmente em comunidades virtuais aos diversos processos midiáticos na internet, que se utilizam dessa metodologia para ampliação do seu universo de leitores.

\section{Fundamentos teóricos da investigação}

Essas mudanças - de distribuição para circulação do conhecimento - sinalizam na direção de um modelo mais aberto de investigação, em que os leitores (ou novos leitores conectados) estão moldando, compartilhando, reconfigurando e remixando conteúdos de mídia. Estes indivíduos, consumidores de conhecimento científico, não estão isolados, mas ligados a grupos virtuais, por meio de redes sociais digitais ou listas on-line na Internet. São verdadeiras "comunidades virtuais" mais amplas que propagam conteúdos e participam de discussões acadêmicas muito além de sua vizinhança geográfica (Jenkins, Ford \& Green, 2014). Segundo Henry Jenkins, o pesquisador Howard Rheingold foi um dos primeiros autores a efetivamente utilizar o termo "comunidade virtual":

"As comunidades virtuais são agregados sociais que surgem da Rede Internet, quando uma quantidade suficiente de gente leva adiante essas discussões públicas durante um tempo suficiente, com suficientes sentimentos humanos, para formar redes de relações pessoais no ciberespaço" (1995, p.20).

Segundo Raquel Recuero (2011), os elementos formadores da comunidade virtual seriam: as discussões públicas; as pessoas que se encontram e reencontram, ou que ainda mantêm contato através da Internet (para levar adiante a discussão); o tempo; e o sentimento. Esses elementos, combinados através do ciberespaço, poderiam ser formadores de redes de relações sociais, constituindo-se em comunidades. As comunidades virtuais são comunidades simbólicas, ou seja, cujos membros "estão conectados primariamente pelas trocas simbólicas (no caso, eletrônicas), mais do que pela interação face a face" (Raquel Recuero, 2011, p. 135). A autora salienta ainda que a interação é considerada um dos elementos da comunidade virtual, além da fronteira 
simbólica para os grupos participantes. É no ciberespaço que as relações são construídas, através da interação mediada pelo computador. Muitos acreditam que a mediação por computador, inclusive, facilita para que os atores demonstrem intimidade e proximidade nas relações sociais on-line e off-line.

Conforme Recuero (2011) nos explica, os interesses homogêneos das pessoas participantes das comunidades virtuais podem aumentar consideravelmente a sensação de empatia, compreensão e suporte mútuo nesses grupos. Ou seja, quanto mais parecidos e mais interesses em comum tiverem os atores sociais, maior a possibilidade de formar grupos coesos com características de comunidade. Lemos (2002) salienta que as comunidades virtuais eletrônicas são agregações em torno de interesse comuns, independentes de fronteiras ou demarcações territoriais fixas. O autor ressalta que o interesse comum e o fim da localidade espacial são uma das características dos sujeitos das comunidades virtuais. Além disso, agrega duas dimensões ao seu entendimento do conceito de comunidade virtual: o território simbólico e a dimensão temporal, onde a comunidade deve durar como comunidade. Ele ainda ressalta que qualquer ambiente onde há comunicação mediada por computador pode ou não ser uma comunidade, dependendo do tipo de relações que está presente (Recuero, 2011).

O poder comunicativo e a ampla tecnologia disponível podem ser adaptados aos métodos qualitativos de coleta e análise de dados. Um inquérito on-line, a exemplo, ao ser compartilhado em listas de e-mails ou em redes sociais transforma os seus participantes em uma comunidade virtual que se faz e desfaz com o final da investigação. Contudo, apenas o investigador consegue visualizá-los dessa maneira, visto que não há interação dentro do grupo, apenas a mediação do processo comunicativo. Esses grupos virtuais devem ser estudados, a partir da perspectiva de sociabilidade na Internet e de re-territorialização em ambientes virtuais.

\section{O processo de territorialização, des-territorialização e re-territorializa- ção na Internet}

As comunidades virtuais forjadas pelos participantes no ciberespaço e possuidoras de fronteiras simbólicas são delineadas por tópicos de interesse. Segundo Castells (2003), o termo "comunidades virtuais" foi associado ao surgimento de novos padrões de interação social ocasionados, principalmente, 
pela Internet. Compreendemos que isso interfere na construção de um novo conceito de comunidade, com menos ênfase no seu componente cultural e mais ênfase no seu papel social.

A investigação on-line é uma possibilidade metodológica para o pesquisador e consiste em um conjunto de práticas materiais e interpretativas que dão visibilidade ao objeto analisado. Essas práticas transformam a pesquisa em uma série de representações. Um mundo desterritorializado, onde não existem barreiras de tempo e de espaço para que as pessoas se comuniquem. Uma nova era que oferece múltiplas possibilidades de investigar em que o espaço físico neste novo paradigma, deixa de ser o local exclusivo para a construção do conhecimento.

Criar um território científico é se apropriar, material e simbolicamente, das diversas dimensões que o conhecimento possa alcançar. O Estado e as instituições tendem sempre a manter territórios como forma de poder e controle. Toda territorialização é uma significação do território (político, econômico, simbólico, subjetivo) e toda des-territorialização, ressignificação, formas de combate à inscrição da vida em um "terroir", linhas de fuga (Lemos, 2005). Ao expandirmos as possibilidades de investigação entre comunidades situadas em cidades, países e continentes diferentes, mas com identidades culturais similares, estamos a criar novos territórios na investigação. Um processo duplo de des-territorialização e re-territorialização, nos quais os ambientes virtuais: listas de e-mails, sites de redes sociais digitais ou links de inquéritos on-line são os novos territórios das investigações (re-territorializados).

Vivemos a era das redes telemáticas, a cibercultura é uma cultura de desterritorialização, mas nos coloca em meio a novas fronteiras controladas e de acesso restrito aos pesquisadores e seus pesquisados. A des-territorialização informacional afeta a política, a economia, o sujeito, os vínculos identitários, o corpo, a arte. A internet é, efetivamente, máquina des-territorializante sob os aspectos político (acesso e ação além de fronteiras), econômico (circulação financeira mundial), cultural (consumo de bens simbólicos mundiais) e subjetivo (influência global na formação do sujeito). Estão em marcha processos de desencaixe e de compressão espaço-tempo na cibercultura (Lemos, 2005).

Um site na internet é sempre uma territorialização ou uma des-re-territorialização, lugar de controle que pode ser uma linha de fuga ao poder instituído, ou a reafirmação desse mesmo poder. Podemos dizer aqui que a cibercultura não apenas destrói hierarquias e fronteiras, mas também as institui 
em um processo complexo de des-re-territorializações. Ou seja, as fronteiras reduzem, estreitam o tempo e o espaço entre as comunidades virtuais, e, dessa forma, criam-se novos territórios para a pesquisa científica. No caso do investigador se utilizar de métodos qualitativos: pesquisas focais, questionários, estudos de caso, inquéritos on-line, entrevistas via-internet ou outras ferramentas de pesquisa, estes lhe servem para legitimar os novos territórios concebidos com o advento da cibercultura.

Os processos de territorialização e des-territorializações nos auxiliam na compreensão melhor a dinâmica social imposta pelas novas tecnologias digitais de comunicação e informação. A partir disso, podemos definir a noção de território de forma abrangente e, como as tecnologias digitais estão criando processos de re-territorialização, em meio a uma dinâmica mais ampla de des-territorialização do ciberespaço. Esses processos mostram como o espaço eletrônico está em interface com o espaço urbano, trazendo possibilidade de novas significações para o espaço acadêmico da investigação (Lemos, 2005).

De acordo com o pesquisador Pierre Lévy (1996), essas características estão intrinsicamente ligadas ao processo de "des-territorialização do presente", visto que não há barreiras de acesso a bens de consumo, produtos e comunicação. O importante nesta sociedade não é a tecnologia em si, mas as possibilidades de interação que elas proporcionam através de uma cultura digital. Segundo Castells as novas tecnologias amplificam as possibilidades de apropriação dos usuários da informação e redefinir as interações sociais:

"O que caracteriza a revolução tecnológica atual não é o caráter central do conhecimento e da informação, mas a aplicação deste conhecimento e informação a aparatos de geração de conhecimento e processamento da informação/comunicação, em um círculo de retroalimentação acumulativa entre a inovação e seus usos". A difusão da tecnologia amplifica infinitamente seu poder ao se apropriar de seus usuários e redefinilos. As novas tecnologias da informação não são apenas ferramentas para se aplicar, mas processos para se desenvolver. (...) Pela primeira vez na história, a mente humana é uma força produtiva direta, não apenas um elemento decisivo do sistema de produção" (2007, p.7).

Dessa forma, concordamos com o autor quando se refere que estamos vivendo uma revolução tecnológica, efeito da globalização das novas identidades da modernidade. O desafio é saber de que maneira todo este arsenal de 
informações que não encontra barreiras de tempo e de espaço poderá contribuir para a democratização do conhecimento científico e as suas experiências empíricas.

Entendemos as novas identidades na contemporaneidade como resultados do fenômeno da globalização, que segundo Anthony McGrew (1992), se refere àqueles processos, atuantes numa escala global, que atravessam fronteiras nacionais, integrando e conectando comunidades e organizações em novas combinações de espaço-tempo, tornando o mundo, em realidade e em experiência, mais interconectado. A globalização implica um movimento de distanciamento da ideia sociológica clássica da "sociedade" como um sistema bem delimitado e sua substituição por uma perspectiva que se concentra na forma como a vida social está ordenada ao longo do tempo e do espaço (Giddens, 1990, p. 64). Essas novas características temporais e espaciais, que resultam na compreensão de distâncias e de escalas importantes da globalização a ter efeito sobre as identidades culturais.

A globalização não é um fenômeno recente. Segundo Stuart Hall (2003), os estados-nação nunca foram tão autônomos ou soberanos quanto pretendiam. O capital nunca permitiu que suas aspirações fossem determinadas por fronteiras nacionais. Assim, tanto a tendência à autonomia nacional quanto a tendência à globalização estão profundamente enraizadas na modernidade (Hall, 2003).

A partir dessas reflexões, lançamos mão de uma pergunta norteadora em nosso estudo para melhor compreensão da pesquisa: "Que impacto desempenha a globalização sobre a construção das identidades culturais nos estudos empíricos?". Conforme cita Stuart Hall (2003), uma das características principais da globalização seria o entendimento da dinâmica do "espaço-tempo", a aceleração dos processos globais, de forma que se sente que o mundo é menor e as distâncias mais curtas, que os eventos em um determinado lugar têm um impacto imediato sobre as pessoas e lugares situados a uma grande distância. $\mathrm{O}$ autor David Harvey argumenta que:

"À medida que o espaço se encolhe para se tornar uma aldeia "global" de telecomunicações e uma "espaçonave planetária" de interdependências econômicas e ecológicas - e à medida em que os horizontes temporais se encurtam até ao ponto em que o presente é tudo que existem temos que aprender a lidar com um sentimento avassalador de compreensão de nossos mundos espaciais e temporais (1989, p. 240)". 
O que é importante para o nosso argumento quanto ao impacto da globalização sobre a construção das identidades nos estudos empíricos é que o tempo e o espaço são também as coordenadas básicas de todos os sistemas de representação da pesquisa.

Os lugares permanecem fixos; é neles que temos "raízes". Entretanto, o espaço pode ser "cruzado" num piscar de olhos. Colocado ao nível do processo de investigação entre indivíduos com identidades culturais similares, mas distantes fisicamente, as identificações "globais" começam a deslocar e, algumas vezes, a apagar, as identidades locais ou nacionais. Na pesquisa, a tendência é em direção a um olhar de hábitos e interesses dos entrevistados influenciados pelo mercado global de estilos, lugares e imagens de mídia e pelos sistemas de comunicação global interligados. As identidades ficam definidas como parte de um fenômeno conhecido como "homogeneização cultural". O que estamos discutindo é a tensão entre as identidades "locais" e "globais", que alteram o processo de construção dos métodos qualitativos de pesquisa. Os interesses de jovens estudantes de Ciências da Comunicação no Brasil são praticamente os mesmos dos jovens europeus. A globalização criou novos modos de articulação e os costumes particulares tornaram-se modos universais.

\section{Metodologia}

Como objeto de análise foram escolhidas duas investigações empíricas de caráter qualitativo que se utilizam de mídias digitais. São estudos acadêmicos direcionados a estudantes de Ciências da Comunicação e Jornalismo do Brasil, Portugal e de outros países. A primeira, em nível de pesquisa pós-doutoral, desenvolvemos no Laboratório de Comunicação e Conteúdos On-line da Universidade da Beira Interior, em Portugal, no ano de 2014, sob a supervisão do professor António Fidalgo (UBI) e com o financiamento da Fundação CAPES do Brasil. A segunda, aplicada em quase 30 países, tem na coordenação brasileira dois professores de cursos de Comunicação Social de universidade públicas brasileiras, Cláudia Quadros da Universidade Federal do Paraná (UFPR) e Fábio Pereira da Universidade de Brasília (UnB).

Ambos os estudos envolvem a participação on-line de entrevistados, a convocação em listas de e-mails de centros de investigação e em sites de redes sociais digitais na Internet. São inquéritos desenvolvidos para um grupo 
específico de pessoas: estudantes de Ciências da Comunicação e Jornalismo nos três níveis de formação: graduação, mestrado e doutoramento. E, tanto na investigação luso-brasileira quanto na brasileira, não fazem-se distinções às fronteiras territoriais. Os inquiridos podem pertencer a realidades distintas e espaços físicos diferentes. Ou seja, fazem parte de comunidades acadêmicas distintas, cidades, países e continentes diferentes. Uma entrevista padrão realizada no Brasil ou na Europa responde a hábitos e costumes similares, que dominam as redes globais. Optar por realizar uma pesquisa em escala mundial, em nossa opinião, não interfere nos resultados finais, pois as evidências nos mostram que a globalização está por toda a parte.

\section{Descrição da primeira investigação: o estudo luso-brasileiro}

$\mathrm{Na}$ investigação luso-brasileira, desenvolvemos uma pesquisa qualitativa com cerca de 17 perguntas, sendo 16 fechadas e apenas uma aberta. A intenção era de verificar os hábitos de consumo de televisão, internet e a rede social Facebook por estudantes brasileiros e portugueses nos três ciclos: graduação, mestrado e doutorado, entre 18 e 35 anos. Com o título "Participação das audiências de TV no Facebook", o inquérito esteve aberto de 03 de abril a 03 de maio de 2014. A convocação dos participantes realizou-se por meio de listas de e-mails: Sociedade Brasileira de Pesquisadores em Jornalismo, Grupo de Pesquisa de Jornalismo On-line da Universidade Federal da Bahia e nos Programas de Pós-Graduação em Comunicação da Universidade Federal do Paraná, Universidade Estadual de Ponta Grossa, Universidade Federal da Bahia, Universidade Federal do Pará, Universidade da Beira Interior (Portugal), Universidade Federal de Pernambuco e Universidade Federal de Santa Catarina. E na página no Facebook do Curso de Comunicação Social Jornalismo e do Programa de Pós-Graduação em Desenvolvimento Regional Sustentável da Universidade Federal do Cariri, Ceará, Brasil. O inquérito teve a adesão de 111 participantes enquanto esteve no ar.

Este estudo representou uma pequena amostra da relação luso-brasileira com a informação sob a perspectiva do uso de suportes variados no consumo de notícia. Esta análise permitiu identificar a visão quanto aos benefícios do uso da tevê e da internet na dieta midiática de informação dos seus participantes. O instrumento de coleta foi criado no Labcom Online da Universidade da Beira Interior, em Portugal. Ao questionário elaboraram-se perguntas fecha- 
das, condicionantes ao nível de resposta do inquirido e ao final uma pergunta aberta (Cajazeira, 2015).

Consideramos consistências lógicas entre as perguntas, que garantiram a qualidade na análise da coleta de dados. Estudaram-se, anteriormente, alguns modelos de questionários desenvolvidos pelo Laboratório de Comunicação e Conteúdos On-line da Universidade da Beira interior, Observatório de Comunicação de Portugal e a Secretaria de Comunicação Social da Presidência da república Federativa do Brasil (Secom). A plataforma do inquérito online (www.inqueritos.ubi.pt), na sua apresentação, incorporou o seguinte texto explicativo dos propósitos da investigação:

\begin{abstract}
"Esta investigação desenvolve uma pesquisa na área de comunicação online e televisão sobre as participações da audiência do jornalismo televisivo no Facebook. A investigação está sediada no LabCom da Universidade da Beira Interior (UBI), Portugal. Solicitamos o preenchimento deste inquérito, até 03 de maio de 2014. Com os resultados obtidos, esperamos contribuir para compreensão da participação da audiência de TV no Facebook. Por isso, agradecemos a sua participação e cuidado no preenchimento do questionário. Todas as respostas são de caráter anônimo e usadas apenas para fins acadêmicos" (Cajazeira, 2015, p.51).
\end{abstract}

$\mathrm{Na}$ análise dos dados, dividimos três formas de consumo: TV, Facebook e suporte de uso. O questionário buscou explorar o consumo de TV. Desenvolveram-se algumas perguntas à compreensão da figura do fã do telejornal. As perguntas foram baseadas no problema da pesquisa, nas hipóteses e nas reflexões realizadas durante a investigação. Os questionamentos versaram sobre os procedimentos quanto às possibilidades oferecidas pela televisão na Era digital. Na última parte do inquérito verificou-se o uso do suporte para ver TV e acessar a internet ou a existência de situações ambivalentes de consumo. Como última pergunta do inquérito, realizou-se na forma aberta, a fim de observar como se posicionava os inquiridos quanto ao hábito de ver TV em duas telas ou ecrãs.

\title{
A descrição da primeira investigação: o estudo brasileiro
}

O projeto de pesquisa internacional, "O estudante do jornalismo no Mundo", no Brasil, tem a coordenação geral de Fábio Pereira (UNB) e Claudia 
Quadros (UFPR). Neste estudo, os estudantes de jornalismo de quase 30 países respondem ao questionário, que tem como objetivo conhecer o perfil dos inquiridos. A pesquisa preserva a identidade dos participantes. Como afirma parte do texto no cabeçalho do inquérito: "Se você é estudante de jornalismo, agradecemos a sua participação. Gostaríamos que respondessem todas as perguntas. O tempo médio de preenchimento é de 10 minutos. A pesquisa preserva a identidade dos participantes". A distribuição do inquérito on-line foi realizada em listas de e-mails de entidades associativas na área de Ciências da Comunicação no Brasil (Compós e SBPJor), Grupo de Pesquisa em Jornalismo On-line (UFBA/Brasil) entre outras, além de partilhamento em sites de redes sociais digitais.

O instrumento de coleta criado na plataforma Google Forms permite a coleta e organização das respostas automatizadas, poupando tempo do investigador e dando-lhe melhores condições para a análise do estudo. Este aplicativo encontra-se no Google Docs, um serviço da Google que permite a edição colaborativa de documentos. Uma das vantagens que verificamos nesse procedimento é a facilidade de uso e a forma organizada e simples com que são apresentadas as respostas. Em nossa análise, no questionário de 31 perguntas, evidenciam-se cinco grandes áreas: escolha profissional, mídia: funções e desejo de atuação profissional, formação profissional do jornalista, dados pessoais e carreira no jornalismo. O questionário esteve aberto nos meses de fevereiro e março de 2015.

O que podemos perceber na análise é que o investigador não precisa mais estar circunscrito a canais convencionais de divulgação de seu trabalho. O processo dá-se desde a sua concepção a leitura dos resultados finais na interação com o computador: a seleção da amostra, o instrumento de coleta, a leitura dos dados, o acompanhamento das respostas, o processamento dos gráficos, a escrita e a divulgação em periódicos on-line com o uso da tecnologia digital.

A informatização mostra-se presente em todas as etapas do processo. Qualquer dado, pode ser divulgado, desde que haja o acesso a uma página na Internet, a qualquer momento, em qualquer lugar. Os horários e locais das entrevistas científicas também são agora de interesse do entrevistado da pesquisa e não mais restrito a acordos com o entrevistador em data e horários pré-estabelecidos. O investigador tem a possibilidade on-line de acompanhar $\mathrm{o}$ andamento da pesquisa à medida que os inquéritos vão sendo respondidos, 
fazendo alterações e observações necessárias no estudo. Por outro lado, verificamos a necessidade de orientações no preenchimento dos questionários aos inquiridos. Como não há possibilidade de haver interação face a face, nos grupos on-line, exige-se a necessidade de um tutorial pedagógico de orientação, caso contrário, algumas perguntas, por falta de entendimento do respondente, podem ficar sem respostas.

\section{Considerações Finais}

A Internet é o apoio principal à investigação científica, ao acesso a artigos das mais variadas áreas, com rapidez e custo baixo. Esse estudo evidenciou que a democratização do acesso aos textos completos de publicações científicas de acesso livre, a instrumentalização, divulgação e distribuição de conteúdo científico em listas de e-mails, sites e redes digitais on-line é uma tendência que permite aumentar a interatividade entre autores e leitores. Proporcionando, dessa forma, uma ampla circulação de conteúdo científico.

Entretanto, faz-se necessário resolver alguns problemas técnicos, como a dificuldade de acesso à Internet em países com número insuficiente de computadores e a falta de investimentos em tecnologia e informatização das cidades. Com o avanço da tecnologia de informação, comunicação e a busca desenfreada de informações, a publicação científica obrigou-se a tomar um novo rumo: estar disponível a todos em qualquer hora e lugar. Sendo assim, favorecem-se investigadores e leitores desse novo ecossistema midiático reconfigurado por mudanças de hábitos de apropriação da informação. Mediante o exposto neste artigo, pode-se afirmar que os processos eletrônicos de produção de estudos científicos possuem grandes vantagens, visto que encontramos um aumento nas comunicações entre investigadores, investigados e novos leitores. O crescimento da pesquisa, com uso de mídias digitais, beneficia não apenas ao investigador, mas a toda comunidade científica, contribuindo com a qualidade do fazer e difundir Ciência.

\section{Referências}

Cajazeira, P.E. (2015). A audiência convergida do telejornal nas Redes Sociais. Covilhã, Portugal : Editora Livros Labcom. 
Castells. M. (2003). A Galáxia Internet: reflexões sobre a Internet, negócios e a sociedade. Rio de Janeiro: Editora Jorge Zahar.

Castells. M. (2007). Sociedade em Rede: A Era da Informação: economia, sociedade e cultura. Rio de Janeiro: Editora Paz e Terra.

Giddens, A. (1990). The Consequence of Modernity. In A identidade cultural na pós-modernidade. Rio de Janeiro: Editora D P \& A.

Hall, S. (2003). A identidade cultural na pós-modernidade. Rio de Janeiro, Brasil: Editora D P\&A.

Harvey, D. (1989). The Condition of Post-Modernity. In A identidade cultural na pós-modernidade. Rio de Janeiro: Editora D P \& A.

Jenkins, H; Green, J. \& Ford, S. (2014). Cultura da Conexão: criando valor e significável por meio da mídia propagável. Rio de Janeiro: Editora Aleph.

Lemos, A. (2002). Cibercultura e Mobilidade. A Era da Conexão. Disponível em: www.intercom.org.br. Acesso: 10.02.2015.

Lemos, A. (2005). Ciber-Cultura- Remix. Disponível em: www.hrenatoh.net. Acesso: 10.02.2015.

Lévy. P. (1996). O que é virtual. São Paulo: Editora 34.

McGrew, A. (1992). A global society. In A identidade cultural na pósmodernidade. Rio de Janeiro: Editora D P \& A.

Recuero, R. (2011). Redes Sociais na Internet. Porto Alegre: Editora Sulina.

Reinhgold, H. (2000). The Virtual Community: Homesteading on the Electronic Frontier. Sociedade em Rede: A Era da Informação: economia, sociedade e cultura. Rio de Janeiro: Editora Paz e Terra. 